\title{
Iridocyclitis in Lepra Reaction Treated with Thalidomide*
}

\author{
JACOB SHESKIN† and H. ZAUBERMAN \\ Hadassah University Hospital, Jerusalem, Israel
}

\begin{abstract}
Thalidomide is shown to be a useful drug in patients with lepromatous leprosy who develop iridocyclitis during a lepra reaction. It should not be given, however, to women in their child-bearing years.
\end{abstract}

Iridocyclitis is one of the more severe manifestations of the lepra reaction (Gomez Orbaneja and Garcia Perez, 1953; Duke-Elder, 1954; Cochrane and Davey, 1964). It may appear spontaneously or while the patient is under treatment.

Before corticosteroids became available, the management of iridocyclitis was unsatisfactory. Local or systemic steroid therapy has, however, considerably improved the outlook. High doses of these drugs are sometimes necessary, and their prolonged use incurs the risk of the well-known side-effects.

Recently, thalidomide has been reported to be effective in control of the general manifestations of the lepra reaction (Sheskin, 1965, 1970; Sheskin and Sagher, 1970). In this report, the effect of thalidomide on the iridocyclitis of patients suffering from reaction in lepromatous or dimorphous leprosy is recorded.

Case 1. A patient, age 59, developed skin lesions in 1955. Six years later, numerous nodular lepromata of the scalp, face, chest and extremities were found. There were no signs of ocular involvement. Smears taken from the ears, nose and one hand revealed acid-fast bacilli, and a biopsy of one of the lesions showed a lepromatous granuloma with numerous acid-fast

*Received for publication 18 August, 1970.

$\dagger$ Department of Dermatology and Venereology, Hadassah University Hospital, and the affiliated Government Hospital for Hansen's Disease, Ministry of Health (Head of Department: Professor Felix Sagher, M.D.), Jerusalem.

$\ddagger$ Eye Department, Hadassah University Hospital, Jerusalem. organisms. The lepromin test was negative. Three months after the institution of sulphone treatment, a reaction consisting of lesions of erythema nodosum leprosum (ENL) appeared on the upper limbs and thighs. The reaction improved gradually with the daily administration of $1.5 \mathrm{mg}$ of dexamethasone and a bi-weekly dose of 20 units of ACTH gel.

In December, 1964, a severe reaction occurred, with polyarthritis and polyneuritis. This was accompanied by severe photophobia and pain in both eyes, caused by bilateral iridocyclitis. Numerous keratitic precipitates and a wellmarked flare in the anterior chamber were seen in both eyes. Treatment was continued with $50 \mathrm{mg}$ of sulphone daily and $400 \mathrm{mg}$ of thalidomide daily for a week. All manifestations of the lepra reaction, including the iridocyclitis, resolved during this time. For the last 8 years the patient has received a daily maintenance dose of $100 \mathrm{mg}$ of thalidomide and 50 to $100 \mathrm{mg}$ of sulphone, and no further reaction has occurred. For the last 4 years, smears taken from the patient have been bacteriologically negative.

Case 2. A widow, now aged 35, had suffered from lepromatous leprosy and lepra reaction for the past 2:3 years.

In October, 1967, at the first examination, diffuse lepromatous infiltration of the face, trunk, and extremities was seen. Atrophy of the thenar and hypothenar eminences, and partial absorption of the distal phalanges, were also present. There was cicatricial entropion of the left eye; the right eye was blind, the pupil was occluded, and numerous posterior synechiae 
were present. In November, 1967, while the patient was receiving a daily dose of $50 \mathrm{mg}$ of sulphone, her temperature rose to $39^{\circ} \mathrm{C}$ $\left(102.2^{\circ} \mathrm{F}\right)$ and erythema nodosum leprosum, polyarthritis, and severe left iridocyclitis appeared.

The eye showed numerous keratitic precipitates and a very pronounced flare in the anterior chamber. The condition improved gradually as the patient was given $20 \mathrm{mg}$ of meticorten daily and a twice weekly dose of 20 units of ACTH gel; the condition recurred, however (without iridocyclitis), and the dose of meticorten was reduced to $10 \mathrm{mg}$ daily, plus 20 units of ACTH gel weekly. In January, 1968, another similar reaction (including acute iridocyclitis) occurred. Steroids were withdrawn and topical $1 \%$ atropine drops were given, with $400 \mathrm{mg}$ of thalidomide daily for a week; sulphone treatment was meanwhile continued. The reaction resolved within 3 days, and the signs of iridocyclitis disappeared within a week. As long as the patient contined to take a maintenance dose of $100 \mathrm{mg}$ of thalidomide daily there was no recurrence of reaction, but stopping the drug was followed by the reappearance of symptoms of reaction, which however improved when thalidomide was again given. Thalidomide has now been given for 2 years, with no recurrence of iridocyclitis.

Case 3. A 52 year old woman who had suffered from lepromatous leprosy for 12 years, was first seen in April, 1969. She presented with nodular lepromata of the forehead and of the extremities. Sulphone treatment, $25 \mathrm{mg}$ daily, was initiated. Two months later signs of reaction developed, the temperature rose to $38.5^{\circ} \mathrm{C}$ $\left(101.3^{\circ} \mathrm{F}\right)$ and lesions of erythema nodosum leprosum appeared on the face and hands. These signs disappeared rapidly after treatment with $300 \mathrm{mg}$ of thalidomide daily. A recurrence, 2 months after the withdrawal of thalidomide, was controlled by further thalidomide therapy.

In December, 1969, during treatment with clofazimine (Geigy B 663) the patient developed incipient reaction, together with iridocyclitis in the right eye. Keratitic precipitates and a moderately strong flare in the anterior chamber were noted. Dexazone, $2 \mathrm{mg}$ daily, and the instillation of $1 \%$ atropine solution, led to improvement. Within $48 \mathrm{hr}$ of $400 \mathrm{mg}$ daily thalidomide being given, the reaction subsided; the iridocyclitis resolved within 6 days. Since then a maintenance dose of $100 \mathrm{mg}$ daily of thalidomide, together with $25 \mathrm{mg}$ sulphones, have been given and no further reaction has occurred.

\section{COMMENT}

Acute iridocyclitis in leprosy is characterized by ocular pain, ciliary injection and an exudative reaction in the anterior chamber. The keratitic precipitates and aqueous flare are difficult to differentiate from infective inflammation of diverse origin (Duke-Elder, 1954). Acute reaction may precipitate a reactivation of a former iritis or trigger the onset of a new inflammatory process in the anterior chamber. In 3 patients suffering from lepromatous leprosy, iridocyclitis either appeared for the first time or recpured during a lepra reaction.

A patient with indeterminate leprosy who had never shown signs of lepra reaction, developed an acute iridocyclitis. The usual dose of thalidomide and atropine during 10 days failed to improve the condition. Treatment was altered to Meticorten, $30 \mathrm{mg}$ daily, plus 20 units ACTH weekly, and local application of a $1 \%$ atropine solution. Improvement followed.

All the reactional lesions in lepromatous leprosy (including neuritis, polyneuritis, erythema nodosum leprosum, orchitis, and iridocyclitis) improved with thalidomide; they failed, however, to improve in a patient suffering from dimorphous leprosy in reaction, and in a patient with indeterminate leprosy in whom iridocyclitis was present. In the 3 patients with lepromatous leprosy described above, the iridocyclitis quickly improved on thalidomide treatment on 4 occasions. Iridocyclitis and other manifestations of the lepra reaction did not recur while the patients were receiving a maintenance dose of this drug. 
No explanation can as yet be offered of the pharmacological effect of thalidomide, but it is thought to be immunosuppressive. In no case were signs of toxicity observed. Side-effects were mild, and in no case was the withdrawal of treatment necessary.

The results observed in these 3 patients justify further trials of thalidomide in iridocyclitis accompanying acute reaction in patients suffering from lepromatous leprosy.

\section{SUMMARY}

Signs of iridocyclitis accompanying other lesions of lepra reaction were seen in 3 patients suffering from lepromatous leprosy-twice in one of the patients and once in each of the others. In a fourth patient with indeterminate leprosy signs of iridocyclitis were found in the absence of a systemic lepra reaction.

Thalidomide therapy in doses of 300 to 400 mg daily, added to the existing DDS treatment, rapidly improved both the ophthalmic condition and the systemic signs of the reaction in the 3 patients with lepromatous leprosy, and daily maintenance doses of 50 to $100 \mathrm{mg}$ of thalidomide (again added to DDS) prevented recurrences of the iridocyclitis. In the patient suffering from indeterminate leprosy, the iridocyclitis was not improved by thalidomide, and it was necessary to administer steroids both locally and systemically to alleviate the condition.

The favourable results of thalidomide administration in the lepra reaction of lepromatous leprosy and iridocyclitis justify further trials, from which, of course, female patients of child-bearing age should be excluded.

\section{ACKNOWLEDGEMENT}

Thanks are due to Professor J. Landau, M.D., for his helpful co-operation.

\section{REFERENCES}

COCHRANE, R. G. and DAVEY, 'T. F. (1964). In Leprosy in Theory and Practice, p. 339. Bristol: John Wright \& Sons.

DUKE-ELDER, w. s. (1954). In Textbook of Ophthalmology. Vol. III. Diseases of the Inner Eye, p. 2321. London: Henry Kimpton.

gomex orbaneJa, J. and garcia perez, A. (1953). In Lepra, p. 265. Madrid, Editorial Pas Montalvo.

Sheskin, J. (1965). Thalidomide in the treatment of lepra reactions. Clin. Pharmacol. Ther. 6, 303.

SHESkin, J. (1964-65). Influencia de la talidomida en la reacción leprosa. Derm. Venez. 4, 210.

SHESkin, J. (1965). Further observations with thalidomide in lepra reactions. Lepr. Rev. 36, 183.

SHESkin, J. and SAGHER, F. (1970). Der gegenwaertige Stand der Thalidomid-Behandlung der Lepra und Leprareaktion. 28. Kongressbericht-Arch. klin. expl. Derm. 237, 312.

SHESkin, J. (1970). Recent experience with thalidomide in Hanser's disease. Int. .J. Derm. 9, 56. 